\title{
Effect of Transition Training Program on Novice Nurses' Working at University Hospitals
}

\section{Magda Sayed Yassin Fawaz ${ }^{1}$; Mona Mostafa Elshazly² ${ }^{2}$ Safaa Mohamed Abdelrahman ${ }^{3}$ Rasha Mohammed Nagib Ali $^{4}$}

1. Master degree Faculty of Nursing- Cairo University;

2. Professor of Nursing Administration, Faculty of Nursing, Ain Shams University,

3. Professor of Nursing Administration, Faculty of nursing - Minia University,

4. Lecturer of Nursing Administration, Faculty of nursing - Minia University

\begin{abstract}
Background: Transition is the period of learning, adjustment and socialization, when the nurse applies, consolidates and increases their existing knowledge, gaining competence (knowledge, skill, and attitude) that is applicable to the nursing practice of the clinical setting or patient population in which they are expected to perform. Aim: investigating effect of effect of transition training program on novice bachlors' degree nurses' working at Minia University Hospitals. Research design: Quasi-experimental research design was utilized in this study. Setting: The study was carried out at Minia University Hospitals. Subject: A convenient sample the study subjects were include all novice nurses (bachelor's degree) in University Hospitals. They are working in the field of nursing practice less than one year $($ no=110). Tools: Two tools were used in this study; nurse's transition training program knowledge questionnaire, and The Casey-Fink Graduate Nurse Experience Survey. Results: There were statistical significance differences in knowledge test scores as well as mean scores of transition role among new graduate nurses. Conclusions: There was a positive effect of transition training program on Novice Nurses. Recommendations: Further attention to academic preparation of nursing new graduate nurses to promote their perceptions about role transition.
\end{abstract}

Key words: Training Program, Transition, Novice Nurses

\section{Introduction}

Today's health care environment is complex and creates demands requiring the professional nurse to be an astute critical thinker, confident and competent when caring for patients and families in multiple health care settings. However, since organizations are faced with increasing demands on resource utilization and simultaneous cost reductions, adequate attention to ensuring successful transition for the newly licensed nurse may be not be appropriately designed, managed, supported or evaluated (Hinkle \& Cheever, 2018).

In recent years, many countries have faced serious nursing staff shortage. Currently, nursing staff shortage is a major healthcare challenge worldwide. Many factors such as hospital managerial style, working in long shifts, nurses' heavy workload, and ineffective coping with transitions contribute to this crisis (Azimian et al., 2014).

Transition is defined as the process of moving from a state to another one which is usually associated with significant changes in goals, roles, and responsibilities (Abel \& Carter-Templeton, 2020). Studies have shown that during transition, different problems such as anxiety, tension, fear, panic, and burnout endanger and undermine nurses' physical and mental health. These problems accelerate staff turnover rate and result in the replacement of experienced nurses by novice ones who do not have enough knowledge, experience, and confidence for working in clinical settings. Given the direct relationship between nurses' quality of working life and the quality of care provided by them, the final outcome of ineffective coping with transition would be inferior quality of nursing care and negative patient outcomes (Mohammadi et al., 2011).

A period of transition occurs when any nurse or midwife commences in a new clinical area. There is no specific time period in which transition occurs - it is an individual process. For nurses or midwives undertaking transition to professional practice as well as a new context,

P a g e $\mid 79$ additional support will be focused on the first three to six months of practice (Villanueva et al., 2015).

A high level of additional support assists in a soft and positive transition to the practice setting as well as to the new role. Several strategies can be helpful in easing and speeding the process of role transition. These strategies include: strengthening internal resources, assessing the organization's resources, culture, and group dynamics, negotiating the role, growing with a mentor and developing management knowledge and skills (Lalonde \& McGillis Hall, 2017).

Research indicates that there is an international gap in how universities prepare student nurses for transitioning from the education system to practice (Wise, 2019). New Graduate Nurses (NGNs) and nursing managers have regularly reported that their education did not fully provide them with the skills required for their transition (Little et al., 2013). The Institute of Medicine in the USA seeks to address the need for the establishment of transition programmes such as nurse residency programmes (NRPs) and internship programmes (INPs) to close this gap (Crimlisk et al., 2017). Transitions programmes are used globally, for example, in Australia, the UK and Sweden. They have various names but all serve the same purpose of closing the gap between theory and practice. Thus NRPs and INPs are important in nursing (Alshawush et al., 2020).

So new graduate nurses are novice practitioners, placed in an environment requiring competent clinical, critical thinking and decision-making skills. New graduate nurses develop these skills during transition to practice programs. In order to provide safe, quality patient care and optimize patient outcomes (AL-Dossary et al., 2013). Transition into practice programs help the new graduate nurse develops confidence and competencies including advanced problem solving, decision-making and critical thinking. The National Council of State Boards of Nursing (NCSBN) and the Institute of Medicine (IOM) have examined training and retention of new graduate nurses and the impact insufficient training may have. 
New graduate nurses who cannot properly transition to the RN role are at risk for increased job stress, leading to practice errors and putting patient safety at risk (Anderson et al., 2012).

\section{Significance of the Study}

Health care Organizations are always short-staffed, and new nurses must be able to act as a nurse and provide patient care in a short period of time. (Barnett et al., 2014). These nurses are entering the healthcare field, receiving an abbreviated orientation, and then expected to take on a full patient assignment. This experience is setting them up for failure. These unprepared novice nurses become frustrated and eventually leave the facility.

More than $40 \%$ of new graduate nurse's report making medication errors, and 50\% they would not recognize life-threatening complications that require intervention, according to data collected by the National Council of State Boards of Nursing. The council also found average turnover rates for nurses in their first year on the job range from $35 \%$ to $60 \%$. So that, the transition training program for new nurses an essential need to become competent, confident, accountable and professional. In addition, they are able to coping with reality shock, improve retention and enhance the nurses' organizational citizenship behaviors (The National Counsil of State Board of Nursing, 2013).

\section{Aim of the study}

This research aims to investigate Effect of Transition Training Program on Novice Bachlors' degree Nurses' Working at Minia University Hospitals.

\section{Research questions:}

The present study was carrying out to answer the following questions: -

1. What are the effects of transition training program on new nurses' working at Minia University Hospitals?

2. Is there the transition training program meet the needs of the novice nurses?

\section{Subject and Methods \\ Research design \\ this study. \\ Quasi-experimental research design was utilized in Setting}

The study was conducting at Minia University Hospitals. The Minia University Hospitals includes four hospitals as follow (Minia University Hospital, Gynecology, Obstetric and Pediatric Minia University Hospital, Urology Hospital, and Cardiothoracic Hospital)

\section{Subjects}

The study subjects were including all novice nurses (bachelor's degree) in Minia University Hospitals. They are working in the field of nursing practice less than one year. Sample size $(\mathrm{no}=110)$, classified as follows (Minia University Hospital 35 nurse; Obstetric\& Pediatric Hospitals 33 nurse; Urology Hospital 32 nurse; and Cardiothoracic Hospital 10 nurse) .

\section{Inclusion criteria \\ - Nurses graduated from Faculty of Nursing \\ - Nurses have one year of experience}

\section{Exclusion criteria}

- Nurses graduated from technical institute of nursing and school of nursing

- Nurses have more than one year of experience

- Nurses refuse to participate in this study

\section{Tools of data collection:}

Two tools were used in this study as follows: nurse's transition knowledge questionnaire and the Casey-Fink graduate nurse experience Survey.

Tool I: Nurses Transition Knowledge Questionnaire, this tool was included two parts as follows:

$1^{\text {st }}$ part was including: Personal characteristics data sheet for studied nurses. It was including; (age, gender, marital status, hospital name, and attendance of any workshops bout communication, documentation critical thinking, and evidence-based practice).

$2^{\text {nd }}$ part: Nurses Transition Knowledge Questionnaire was developed by the researchers based on related literature (Anderson et al., 2012; AL-Dossary et al., 2013; Zuriguel Perez et al., 2015; Alkouri et al., 2016; Carter et al 2016; \& Amoah et al., 2018) to assess studied nurses level of knowledge regarding communication, documentation, critical thinking, and evidence based practice during different periods of measurement, (before program, immediately after program, and after three months of program implementation).The questions were related to: communication, documentation, critical thinking, and evidence based practice. This questionnaire composed of 40 questions (24 multiple choice questions and 16 questions true and false). The questions were scored as two for the correct answer and one for the incorrect answer. The scoring system of this tool was divided as follows

- Unsatisfactory knowledge $(<60 \%)$.

- $\quad$ Satisfactory knowledge $(>60 \%)$.

Low scoring means studied nurses had unsatisfactory knowledge and high scoring means studied nurses had satisfactory knowledge.

\section{Tool II: The Casey-Fink Graduate Nurse Experience Survey:}

This tool was developed by Casey et al., (1999) and revised by Altier, (2002) and again by Keller, (2006). The tool contains three sections: comfort/confidence; job satisfaction; and role transition to measure the role of transition during different periods of measurement, (before program, immediately after program, three months of program implementation). Twenty-four of the tool questions utilized a 5 -point Likert scale ranging as (Strongly agree $=5$, Agree $=4$, Not sure $=3$, Disagree $=2$, Strongly disagree $=1$ ) and score was reversed for negative items to measure confidence and nine job satisfaction items utilized a 5-point Likert scale ranging as (Very satisfied $=5$, Moderately satisfied $=4$, Neither Satisfied nor Dissatisfied $=3$, Dissatisfied $=2$, Very dissatisfied $=1$ ). The remaining items consisted of four multiple-choice questions for role transition.

\section{Scoring system:}

The scoring system of the part of confidence was classified into 3 levels as a follow: Low level of confidence 
(24-56), Moderate level of confidence (57-88) and High level of confidence (89-120)

The scoring system of the part of job satisfaction was classified into 3 levels as a follow: Low level of job satisfaction (9-21), Moderate level of job satisfaction (22-33) and High level of job satisfaction (34-45).

\section{Validity of the tool:}

Tools were tested for the face validity by a jury of five experts in Nursing Administration. The jury was consisted from one professor, one assistant professor of Nursing Administration Department - Faculty of Nursing Minia University and three professors of Nursing Administration Department - Faculty of Nursing - Assuit University.

Tools face validity was done to identify the degree to which tools supposed to be measured. The tools were examined for content coverage, sequence of items, clarity, relevance, applicability, wording, length, format, and overall appearance. Based on experts' comments and recommendations; minor modifications had been made such as rephrasing and rearrangements of some sentences.

\section{Reliability:}

Internal consistency of interview questionnaire was assessed with the Cronbach's alpha coefficient. Cronbach's alpha coefficient of 0.00 indicates no reliability and a coefficient of 1.00 indicates perfect reliability. However, a reliability coefficient of 0.70 is acceptable. Cronbach's alpha for reliability testing was performed for each tool and the results was as represented s following ( $1^{\text {st }}$ tool knowledge questionnaire was 0.891, and 2nd tool The CaseyFink Graduate Nurse Experience Survey was 0.898).

\section{Pilot Study}

The pilot study for the questionnaires was conducted on $(10 \%)$ as 11 nurse which were included in the study subjects. They were selected randomly from the different hospitals department in order to check and ensure the clarity and applicability of the tools; as well as to identify obstacles and problems that may be encountered during data collection and estimate the time needed to fill the questionnaires. In the light of the findings of the pilot study, no modification was done in the tools and the tools were put in their final form; so, the pilot study was included in the actual study.

\section{Procedure}

The study was conducted through the following phases: Assessment and planning phase, implementation phase, and evaluation phase.

\section{Assessment and planning phase}

- An official permission obtained from Dean of the Faculty of Nursing, the Directors of Minia University Hospitals.

- The tool of knowledge developed by the researchers based on related literature through three months from the beginning of June 2019 to the end of August 2019

- Pre-test was done from participants; and the researchers collected data in three months from the beginning of September 2019 to the end of November 2019 by used two tools survey and knowledge test was taking for each from 25 to 30 minutes.

- A review of the related literature which covering various aspects of the problem was done. The review of literature developed in seven months from beginning of February 2020 to end of August 2020.

- The researchers were prepared the timetable of the program.

- The researchers were prepared the learning environment in which the study was conducted, and all needed resources as (conference room in the hospitals and data show).

Implementing phase (implement of the training program):

- The study subjects of studied nurses were divided into 2 subgroups in each hospital, each subgroup contained from 15 to 17 nurse on three hospitals but the hospital of cardiothoracic the subgroup contain 5 nurses, and the researchers applied the program for each subgroup on separate time.

- All sessions were implemented according to the working time of the participants; and it was done in teaching rooms of the hospital's education building. Each session takes about 2 hours.

- The researchers explained objectives of the educational program to the studied nurses; content and time table

- At the beginning of each session, the objectives of the session were explained. The feedback before each session was obtained about the previous session and at the end of each session there were summary about the current session.

- The training program was implemented in two months from the beginning of September 2019 to the end October 2019.

\section{Evaluation phase:}

Evaluating of the immediate effect of training program on studied nurses to assess knowledge about the topics of the program was done using the two tools. It was filled in end of October 2019.

The follow up was conducted after three months of the program implementation to assess knowledge about the topics of the program was done using the two tools. It was filled in the end of January 2020.

\section{Ethical considerations}

- Official permission was granted approval by the Ethical Committee of the Faculty of Nursing, Minia University

- The studied nurses were informed that their participation in the study was completely voluntary and there was no harm if they not participated in the study.

- The studied nurses were informed about the withdrawal procedures if they decided to leave the study at any time before, during or after the completion of data collection,

- Oral consent was obtained from studied nurses after explaining the nature and benefits of the study.

- Confidentiality of data, privacy, identity, voluntary participation and right to refuse to participate in the study was emphasized to subjects. 
was prepared. Data were fed to the computer and statistical analysis was performed using Statistical Package for Social Sciences (SPSS version 25). Significance of the obtained results was judged at the $5 \%$ level of significance. Probability (p-value) less than 0.05 was considered significant and less than 0.001 was considered highly significant.

checks, making corrections whenever possible. Raw collected data were coded and scored and a coding instruction manual

\section{Results}

Table (1): Personal characteristics data of the studied nurses at Minia University Hospitals (N=110).

\begin{tabular}{|l|l|l|}
\hline Personal characteristics & Studied nurses $(\mathbf{N}=\mathbf{1 1 0})$ \\
\hline Age & No \\
\hline - 22-23yrs & 92 & $\mathbf{8 3 . 6}$ \\
- 24 yrs & 18 & 16.4 \\
\hline Mean \pm SD & $\mathbf{2}$ \\
\hline Gender & 31 & 28.2 \\
\hline$\quad$ Male & 79 & $\mathbf{7 1 . 8}$ \\
\hline$\quad$ Female & 90 & $\mathbf{8 1 . 8}$ \\
\hline Marital statues & 20 & 18.2 \\
\hline Single & & \\
\hline
\end{tabular}

Table (1) shows regarding, that the majority of the studied nurses $(83.6 \%)$ are in age group ranged between $22-23$ years; $(71.8 \%)$ of them are females; also, the majority $(81.8 \%)$ of them are single.

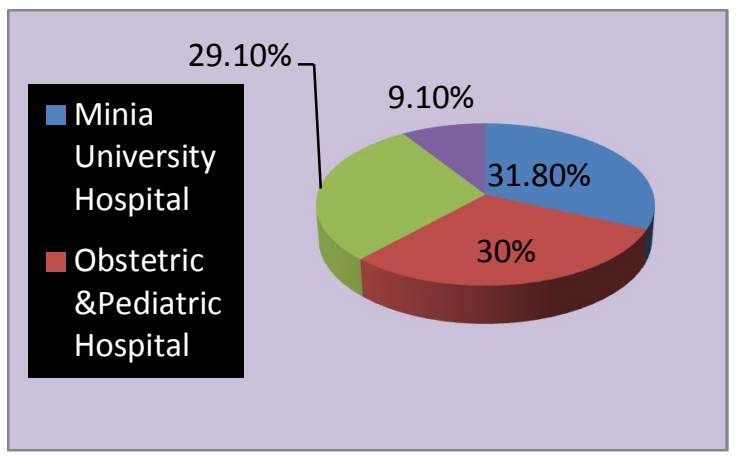

Figure(1): Percentage distribution of the studied nurses regarding to their Hospital name $(\mathrm{N}=110)$

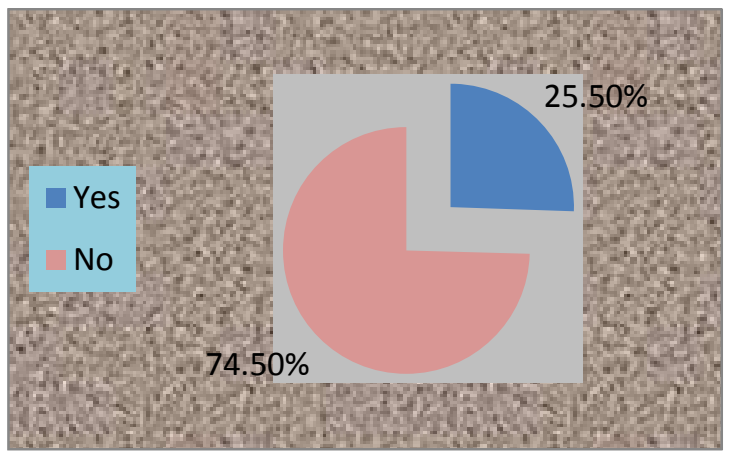

Figure(2): Percentage distribution of the studied nurses regarding to attendance of workshops $(\mathrm{N}=110)$.

As regards to figure (1), nearly one third of the studied nurses working at Minia University Hospital, Obstetric \&Pediatric Hospital, and Urology Hospital as $(31.8 \%, 30 \% \& 29.1 \%)$ respectively. Moreover figure (2) shows that, about three quarters (74.5\%) of the sample don't attended any workshops.

Table (2) Mean scores of studied nurses' knowledge during different times of testing $(\mathbf{N}=110)$

\begin{tabular}{|l|l|l|l|l|l|}
\hline \multirow{2}{*}{ Variable } & $\begin{array}{l}\text { Pre program } \\
\text { (N=110) }\end{array}$ & $\begin{array}{l}\text { Immediate Post } \\
\text { program } \\
(\mathbf{N}=110)\end{array}$ & $\begin{array}{l}\text { After } \\
\text { months } \\
\text { program (N=110) }\end{array}$ & PNOVA \\
& Mean+SD & Mean+SD & Mean+SD & P \\
\hline Communication & $12.2+2.38$ & $18.3+1.82$ & $18.1+2.59$ & 371.6 & $0.001 * *$ \\
\hline Documentation & $12.1+2.17$ & $18.6+1.84$ & $18.05+2.59$ & 421.03 & $0.001 * *$ \\
\hline Critical thinking & $11.5+1.56$ & $18.5+1.82$ & $18.0+2.59$ & 577.05 & $0.001 * *$ \\
\hline Evidence based practice & $11.4+1.51$ & $18.6+1.84$ & $18.1+2.59$ & 588.8 & $0.001 * *$ \\
\hline
\end{tabular}

Table (2) Indicates that there is an increase in studied nurses' knowledge about communication mean score from (12.2 \pm 2.38 ) pre-program implementation to be immediately after the program (18.3 \pm 1.82$)$; and $(18.1 \pm 2.59)$ after three months of program implementation with high statistic difference $(\mathrm{P}=0.001)$. While studied nurses are knowledge about documentation mean score from $(12.1 \pm 2.17)$ pre-program implementation to be immediately after the program (18.6 \pm 1.84$)$; and (18.05 \pm 2.59$)$ after three months of program implementation with high statistical difference $(\mathrm{P}=0.001)$.

Moreover, from table (2) it is noted that there is an increase in studied nurses' knowledge about critical thinking mean score from (11.5 \pm 1.56$)$ pre-program implementation to be immediately after the program (18.5 \pm 1.82$)$; and decreased to be (18.0 \pm 2.59$)$ after three months of program implementation with high statistic difference $(\mathrm{P}=0.001)$, also studied nurses' knowledge about evidence based practice mean score from (11.4 \pm 1.51$)$ pre-program implementation to be immediately after the program (18.6 \pm 1.84$)$; and $(18.1 \pm 2.59)$ after three months of program implementation with high statistic difference $(\mathrm{P}=0.001)$. 


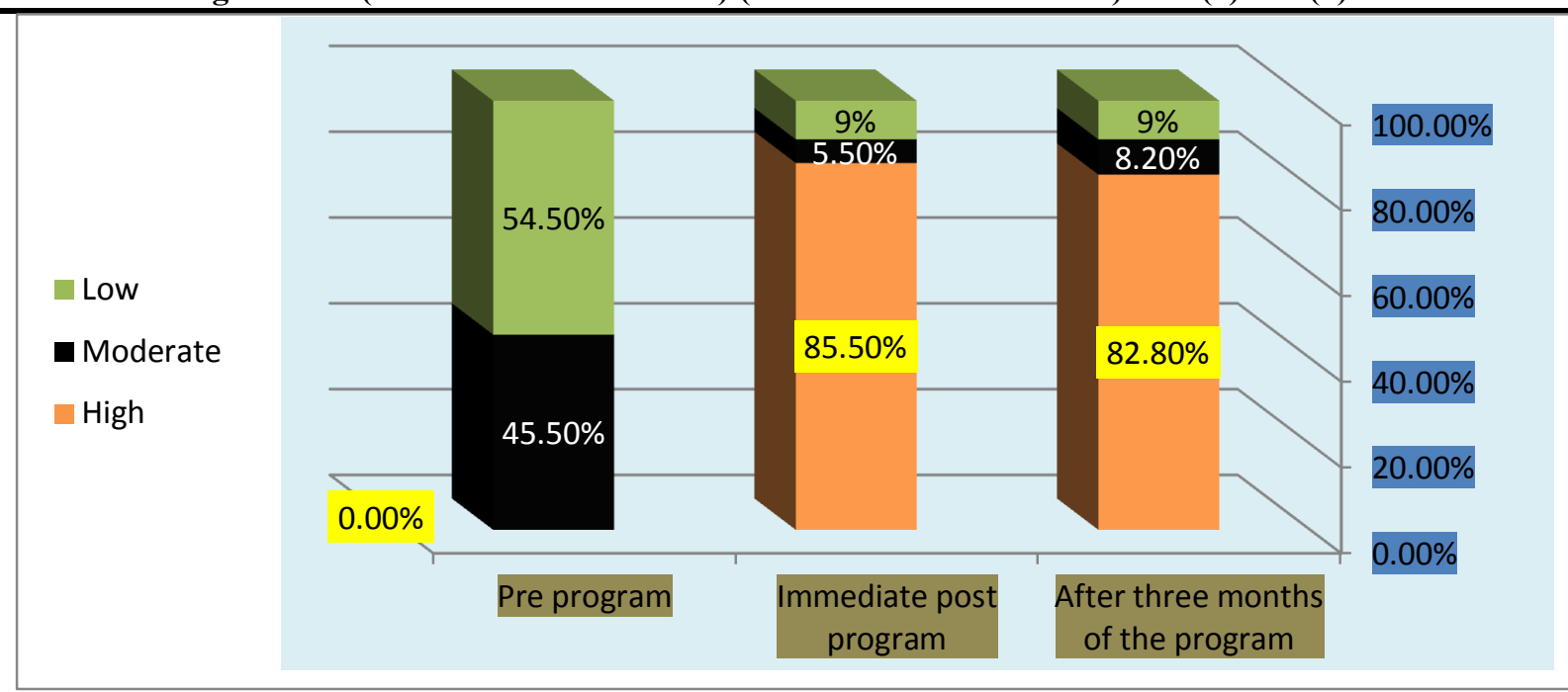

\begin{tabular}{|c|}
\hline P-value (Wilcoxon) \\
\hline $\mathrm{P}_{1}=0.001 * * \quad(8.645)$ \\
\hline $\mathrm{P}_{2}=0.001 * * \quad(8.587)$ \\
\hline
\end{tabular}

$\mathbf{P}_{\mathbf{1}}=$ pre and immediately post the program implementation $\mathbf{P}_{\mathbf{2}}=$ pre and after three months of program implementation $* \mathbf{p} \leq 0.05$ (significant)

Figure (3): Percentage distribution of studied nurse's perception regarding to total comfort/ confidence level during different times testing $(\mathrm{No}=110)$

Figure (3) summarizes that none $(0 \%)$ of studied nurses have high level of confidence before program implementation compare with $(85.5 \%)$ immediately post program implementation, as well as $(82.8 \%)$ after three months of program implementation, with statistically significant differences $(\mathrm{p}=0.001)$ between pretest and different times of testing) pretest with immediately posttest, and pretest with after three months of posttest).

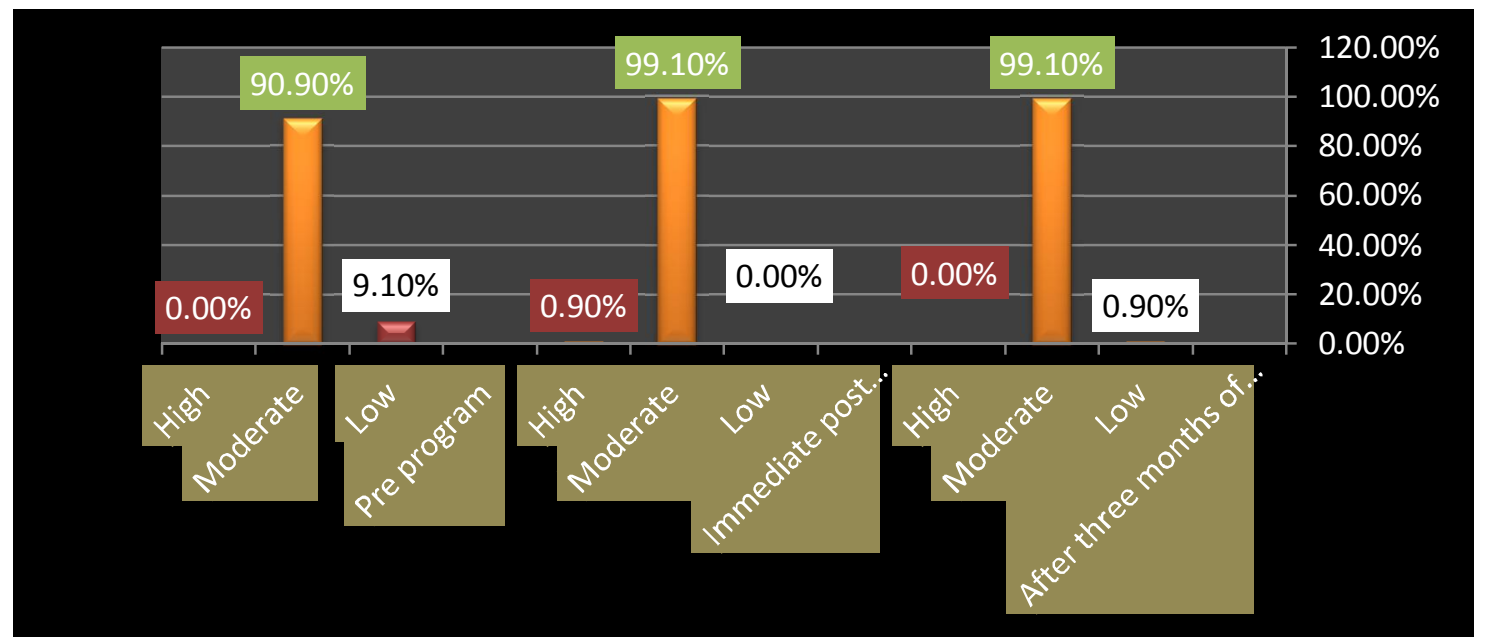

Figure(4) Percentage distribution of studied nurse's perception regarding total of how satisfied are staff with the following aspects of their job during different times of testing $(\mathrm{No}=110)$

Figure (4) illustrates that the majority $(90.9 \%)$ of the sample have moderate satisfied about the aspects of their job before program implementation compare with $(99.1 \%$ \& $99.1 \%)$ immediate after program implementation and after three months of program implementation

Table (3) Percentage distribution of studied nurse's perception regarding role of transition $(\mathrm{N}=110)$

\begin{tabular}{|c|c|c|c|c|c|c|c|c|c|c|}
\hline Items & \multicolumn{2}{|c|}{$\mathbf{A}$} & \multicolumn{2}{|c|}{ B } & \multicolumn{2}{|c|}{$\mathrm{C}$} & \multicolumn{2}{|c|}{ D } & \multicolumn{2}{|c|}{$\mathbf{E}$} \\
\hline Pre program & & & & & & & & & & \\
\hline $\begin{array}{l}\text { 1-What difficulties, if any, are you } \\
\text { currently experiencing with the } \\
\text { transition from the "student" role to } \\
\text { the "RN" role? }\end{array}$ & $\begin{array}{l}55 \\
(50)\end{array}$ & $\begin{array}{l}55 \\
(50)\end{array}$ & 0 & $\begin{array}{l}110 \\
(100)\end{array}$ & $\begin{array}{l}55 \\
(50)\end{array}$ & $\begin{array}{l}55 \\
(50)\end{array}$ & 0 & $\begin{array}{l}110 \\
(100)\end{array}$ & $\begin{array}{l}10 \\
(9.1)\end{array}$ & $\begin{array}{l}100 \\
(90.9)\end{array}$ \\
\hline $\begin{array}{l}\text { 2-What could be done to help you } \\
\text { feel more supported or integrated } \\
\text { into the unit? }\end{array}$ & 0 & $\begin{array}{l}110 \\
(100)\end{array}$ & $\begin{array}{l}55 \\
(50)\end{array}$ & $\begin{array}{l}55 \\
(50)\end{array}$ & 0 & $\begin{array}{l}110 \\
(100)\end{array}$ & $\begin{array}{l}55 \\
(50)\end{array}$ & $\begin{array}{l}55 \\
(50)\end{array}$ & & \\
\hline
\end{tabular}


Minia Scientific Nursing Journal (Print - ISSN 2537-012X) (Online - ISSN 2785-9797) Vol. (9) No. (1) June 2021

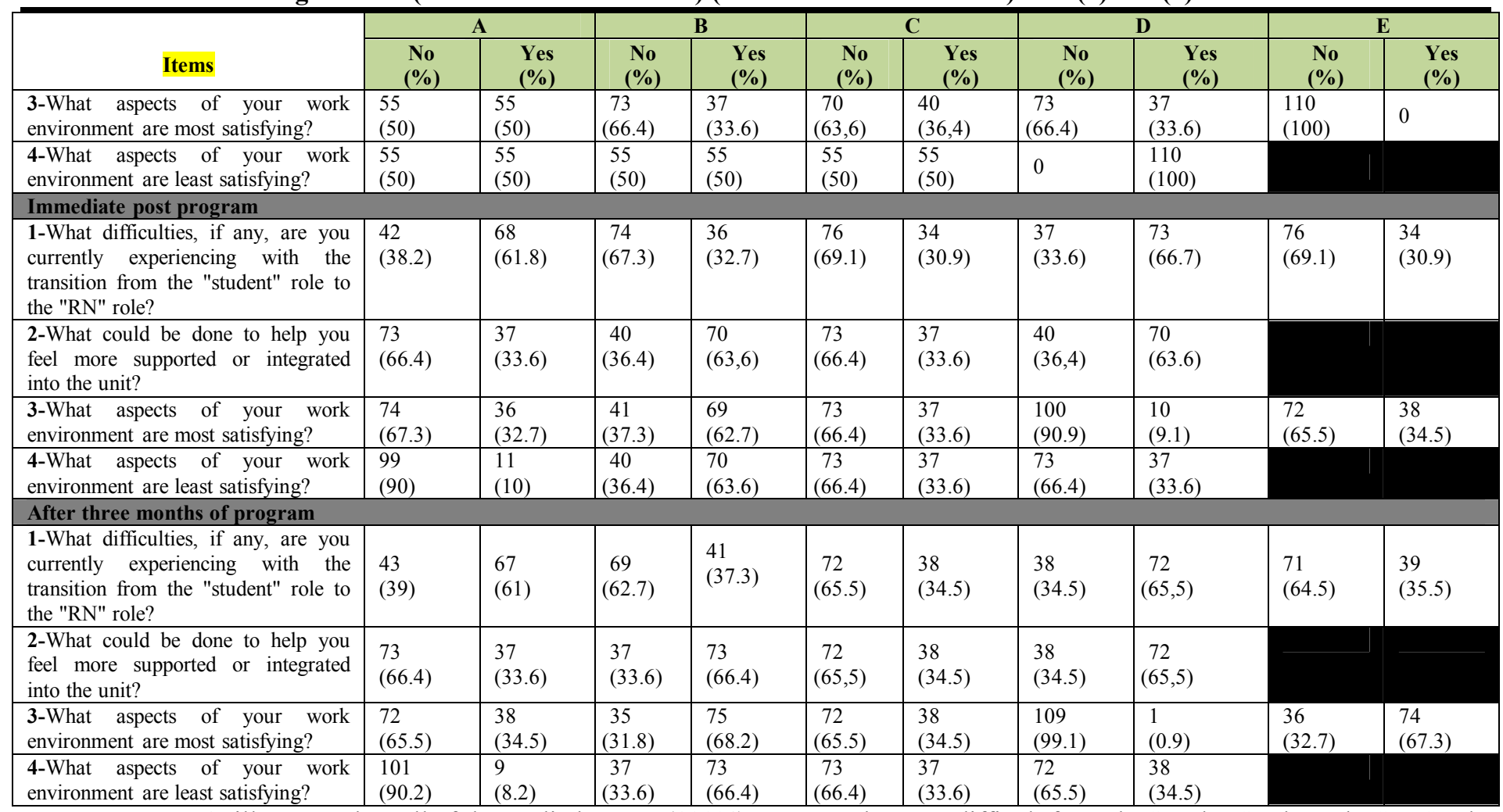

Table (3) illustrates that, all of the studied nurses (100\%) response the most difficult from the "student" role to the "RN" role are lack of confidence (e.g. communication skills, delegation, knowledge deficit, critical thinking) and fears (e.g. patient safety); while the response toward the most things that help to integrated in the unit are improved orientation (e.g. preceptor support and consistency, orientation extension, unit specific skills practice) and unit socialization (e.g. being introduced to staff and MDs, opportunities for staff socialization), also (50\%) of them response toward the most aspect which satisfied in their work environment are peer support (e.g. belonging, team approach, helpful and friendly staff). While all of the studied nurses (100\%) of sample response toward the least aspect which satisfied in their work environment are the orientation (inconsistent preceptors, lack of feedback) before program implementation.

More over immediate after the program implementation, about two thirds of the sample (66.7\%) response the most difficult from the "student" role to the "RN" role are fears (e.g. patient safety); while (63.6\%) of the sample response toward the most things that help to integrated in the unit are increased support (e.g. manager, RN, and educator feedback and support, mentorship), and improved work environment (e.g. gradual ratio changes, more assistance from unlicensed personnel, involvement in schedule and committee work), also (62.7\%) of them response toward the most aspect which satisfied in their work environment are patients and families (e.g. making a difference, positive feedback, patient satisfaction, patient interaction). While (63.6\%) of sample response toward the least aspect which satisfied in their work environment are System (e.g., outdated facilities and equipment, small workspace, charting, paperwork) immediate after program implementation.

Table (4): Correlation between studied nurses knowledge confidence/ comfort level, job satisfaction during different times of testing $($ No $=110)$

\begin{tabular}{|c|c|c|c|c|c|}
\hline \multirow[t]{2}{*}{ Variables } & \multicolumn{2}{|c|}{ Knowledge } & \multicolumn{2}{|c|}{ Confidence/comfort } & \multirow{2}{*}{$\begin{array}{l}\text { How satisfied are staff with } \\
\text { the following aspects of their } \\
\text { job } \\
\begin{array}{l|l}\text { r } & \text { p }\end{array}\end{array}$} \\
\hline & $\mathbf{r}$ & $\mathbf{p}$ & $\mathbf{r}$ & $\mathbf{p}$ & \\
\hline \multicolumn{6}{|l|}{ Preprogram implementation } \\
\hline \multicolumn{6}{|l|}{ Knowledge } \\
\hline Confidence/comfort & .304 & $.001 * *$ & & & \\
\hline $\begin{array}{l}\text { How satisfied are staff with the following } \\
\text { aspects of their job }\end{array}$ & $-.109-$ & $.257 \mathrm{NS}$ & .040 & $.682 \mathrm{NS}$ & \\
\hline \multicolumn{6}{|l|}{ Immediate post program implementation } \\
\hline \multicolumn{6}{|l|}{ Knowledge } \\
\hline Confidence/comfort & $.320 * *$ & $.001 * *$ & & & \\
\hline $\begin{array}{l}\text { How satisfied are staff with the following } \\
\text { aspects of their job }\end{array}$ & 118 & $.218 \mathrm{NS}$ & .045 & $643 \mathrm{NS}$ & \\
\hline \multicolumn{6}{|c|}{ After three months of the program implementation } \\
\hline \multicolumn{6}{|l|}{ Knowledge } \\
\hline Confidence/comfort & .670 & $.001 * *$ & & & \\
\hline $\begin{array}{l}\text { How satisfied are staff with the following } \\
\text { aspects of their job }\end{array}$ & .041 & .670 & .000 & .996 & \\
\hline
\end{tabular}

Table (4) shows that there is positive correlation between studied nurses' total knowledge and confidence during different times of testing $(\mathrm{P}=0.001)$. 
Discussion

Transition from being a student to working as newly qualified nurse is not just a phenomenon that begins with familiarization of the new workplace but it is an experience that influences the professional lives of intern nurses. Intern nurses are new graduate nurses or novice nurses who have just began a career in nursing after attaining a nursing qualification. During the first year of nursing most countries including Egypt have internship programs to support intern nurses in their transition. Internship programs usually last for one year, during which intern nurse must adapt to the new role and deal with the emotions and challenges of professional integration. The transition from being a nursing student to working with real patients can range from just feeling uncomfortable to a highly shocking experience (Gaundan\& Mohammadnezhad, 2018).

Regarding personal characteristics data, that the majority of the studied nurses are in age group ranged between 22-23 years; less than three quarters of them are females; also, the majority of them are single. Moreover, nearly one third of the nurse's studied working at Minia University Hospital, Obstetric \&Pediatric Hospital, and Urology Hospital. Finally, about three quarters of the sample doesn't attend any workshops.

The current study indicated that there is an increase in studied nurses' mean score of knowledge about communication, documentation, critical thinking and evidence-based practice from pre-program implementation to be immediately after the program and after three months of program implementation.

From the researchers' point of view, regarding new graduated nurse knowledge, the training program provide new graduated nurse with communication, documentation critical thinking and evidence-based practice knowledge. In which communication enhance new graduated nurse how deal with the patients, peers, physicians, superior and subordinates, while documentation require for all works of the nurse to provide legal protection for them. As well as critical thinking refresh new graduated nurse knowledge and apply problem solving process moreover take action in the critical situations. Finally, evidence-based practice enhances nurse decision making and update their knowledge related to nursing science.

This result might be attributed to the fact that the new graduated nurses before program implementation don't recognize the importance of communication, documentation critical thinking and evidence-based practice for their nursing work, patients and the organization. Also, the new graduated nurse had low knowledge about communication, documentation critical thinking and evidence-based practice, because they had reality shock between their studying and actually work environment. Moreover, there is no update or refreshment of their knowledge; as well there is absence of inservice training at their work areas.

The current finding agreement with Kay\& Yearous, (2011), they mentioned that nurses had low knowledge about documentation also principle of documentation so nurses need to training program in which improves their knowledge about documentation. Moreover, Rickbeil and Simones, (2012), they stated that EBP increases the ability of nurses to be more updated with the most recent and scientific researches and to involve the patient in the nursing process which enables her to introduce efficient and powerful nursing care.

Moreover Hutchison, (2013) stated that transition to become registered nurses (RNs) are graduating novice nurses who need critical thinking skills to solve patient problems. This result supported with Sheldon \& Hilaire, (2015), stated that communication program should also be included in the workplace for newly graduated nurses as they transition for enhance their knowledge and $\mathrm{n}$ practice about communication skills. Also, the present results parallel with Morsy et al., (2015), they mentioned that regarding total knowledge score, the present study represented improvement in the total knowledge level immediately after implementation of the educational program compared with before the implementation of the educational program.

In addition, Mahmoud \& Mohamed, (2017) they concluded their study with more than three quarters of the nurses had an ambivalent disposition toward critical thinking, and most nurses' scores indicated a negative tendency towards truth-seeking. So, the findings pointed for upgrading nurses' critical thinking through educational programs and a need for more problem-based learning with advanced teaching strategies in clinical areas. Furthermore Chu et al., (2018), they stated that communication knowledge significantly improved post intervention.

The current finding summarized that none of studied nurses have high level of confidence before program implementation compare with the majority of them immediately post program implementation had high level of confidence, as well as slightly decrease after three months of program implementation, with statistically significant differences $(p=0.001)$ between pretest and different times of testing) pretest with immediately posttest, and pretest with after three months of posttest). From the researchers' point of view newly graduated nurses had low knowledge about communication, documentation critical thinking and evidencebased practice before program and increase immediately post program implementation

The current finding symmetrical with Tocco et al., (2013), they stated that confidence will then slowly increase as all the new information is addressed and accounted for. Also, DeCleene Huber et al., (2015), they mentioned that knowledge and confidence of the students gain in their educational training and clinical experience affect their future use of EBP as clinicians.

The current finding illustrated that the majority of the sample had moderate satisfied about the aspects of their job before program implementation, immediate after program implementation and after three months of program implementation. This might be newly graduated nurses had found themselves in highly complex situations as a result of factors such as high patient acuity, scarcity of nurses, limited available resources. fear of making mistakes, clinical knowledge and skills deficits, and advances in healthcare technology and specialties

The current finding symmetrical with Tastan et al., (2013), they stated that stressful events and the negative feelings experienced by newly graduated nurses affect their feelings and perceptions about being a part of an institution and their professional satisfaction, professional relations, views about the profession, professional and personal development, and their private and social lives. In turn, these negative events and feelings lead to lower levels of professional satisfaction and to leaving the profession

The current finding showed that there is positive correlation between nurse's total knowledge and confidence during different times of testing. From the researchers' point of view increase knowledge led to increase decision making 
and deal with critical situation. The present results parallel with Phillips et al., (2014), they stated that nurse have selfconfidence because of their formal educations.

\section{Conclusion:}

There were statistical significance differences in knowledge test scores as well as mean scores of transition role among new graduate nurses. There was a positive effect of transition training program on novice nurses. Moreover, there is positive correlation between nurse's total knowledge and confidence during different times of training program

\section{Recommendations}

Based on the study results the following recommendations are advised that:

- Create and design a job description for new graduate nurses should be provided and explained to them during the orientation program.

- Further attention to academic preparation of new graduate nurses to promote their perceptions about role transition.

- Conduct an orientation program for nurse students before new graduate nurses' program and before each training period to explain objectives, roles and responsibilities and discuss nurse students' expectation.

- Clarify for the role expectations by using role models, role repetition, preceptors, mentors to keep working with professional standards and values.

- Encourage to attend seminars and/or symposiums that focus on transitioning the graduate nurse to professional nursing practice

\section{References}

(1) Abel, S. E., \& Carter-Templeton, H. (2020). Implementing a Transition-to-Practice Program for Novice Clinical Nurse Specialists: A Pilot Project. Clinical Nurse Specialist, 34(4), 162-169.

(2) AL-Dossary, R., Kitsantas, P., \& Maddow, P. J. (2013). The Impact of Residency Programs on New Nurse Graduates' Clinical Decision Making and Leadership Skills: A Systematic Review. Nurse Education Today. Retrieved

from http://dx.doi.org/10.1016/j.nedt.2013.10.006

(3) Alshawush, K. A., Hallett, N., \& Bradbury-Jones, C. (2020). Impact of transition programmes for students and new graduate nurses on workplace bullying, violence, stress and resilience: a scoping review protocol. BMJ open, 10(10), e038893.

(4) Altier, M.E., \&Krsek, C.A. (2002). Effects of a 1-year residency program on job satisfaction and retention of new graduate nurses. Journal for Nurses in Staff Development, 22(2), 70-77

(5) Amoah, V. M. K., Anokye, R., Boakye, D. S., \& Gyamfi, N. (2018). Perceived barriers to effective therapeutic communication among nurses and patients at Kumasi South Hospital. Cogent Medicine, 5(1), 1459341.

(6) Anderson, G., Hair, C., \& Todero, C. (2012). Nurse Residency Programs: An Evidence Based Review of Theory, Process, and Outcomes. Journal of Professional Nursing, 28(4), 203-212. Retrieved October 7, 2013

(7) Azimian, J., Negarandeh, R., \& Fakhr-Movahedi, A. (2014). Factors affecting nurses' coping with transition: An exploratory qualitative study. Global journal of health science, 6(6), 88.

(8) Barnett, J. S., Minnick, A. F., \& Norman, L. D. (2014). A Description of U. S. PostGraduation Nurse Residency
Programs. Nursing Outlook, 62, 174-184. Retrieved November 12, 201

(9) Casey, K., Fink, R., Krugman, M., \&Propst, J. (1999). The graduate nurse experience. The Journal of Nursing Administration, , 34(6)

(10) Chu, C. H., Sorin-Peters, R., Sidani, S., De La Huerta, B., \& McGilton, K. S. (2018). An interprofessional communication training program to improve nurses' ability to communicate with stroke patients with communication disorders. Rehabilitation Nursing Journal, 43(6), E25-E34.

(11) Crimlisk, J. T., Grande, M. M., Krisciunas, G. P., Costello, K. V., Fernandes, E. G., \& Griffin, M. (2017). Nurse residency program designed for a large cohort of new graduate nurses: Implementation and outcomes. Medsurg Nursing, 26(2), 83.

(12) DeCleene Huber, K. E., Nichols, A., Bowman, K., Hershberger, J., Marquis, J., Murphy, T., ... \& Sanders, C. (2015). The correlation between confidence and knowledge of evidence-based practice among occupational therapy students. The Open Journal of Occupational Therapy, 3(1), 5.

(13) Gaundan, G., \& Mohammadnezhad, M. (2018). Reality shock: a transitional challenge faced by intern nurses at Labasa hospital, Fiji. International Journal of Healthcare and Medical Sciences, 4(9), 158-164.

(14) Goodwin, Esola, M., Deely, M., \& Powell, N. Progress meetings: Facilitating role transition of the new graduate. The Journal of Continuing Education in Nursing, 2009. 40(9). doi: 10.3928/00220124-20090824-04

(15) Hinkle, J. L., \& Cheever, K. H. (2018). Brunner and Suddarth's textbook of medical-surgical nursing. Wolters kluwer india Pvt Ltd.

(16) Honour, D. R. (2015). Implementation of the transition to practice regulatory model for preceptors in a rural setting (Doctoral dissertation, University of Southern Mississippi).

(17) Hutchison, B. E. (2013). Critical thinking skill acquisition in accelerated LVN to RN nursing programs: An evaluative case study (Doctoral dissertation, University of Phoenix).

(18) Kay, S., \& Yearous, G. (2011). School nursing documentation: knowledge, attitude, and barriers to using standardized nursing languages and current practices. Lowa Research Online.[online] Available at: htp. ir. uiowa. edu/etd/3411 (Accessed: August 8, 2016).

(19) Keller, J.L., Meekins, K., \& summers, B. (2006). Pearls and pitfalls of a new graduate academic residency program. The Journal of Nursing Administration, 36(12), 589-598

(20) Lalonde, M., \& McGillis Hall, L. (2017). The socialisation of new graduate nurses during a preceptorship programme: strategies for recruitment and support. Journal of clinical nursing, 26(5-6), 774-783.

(21) Little, J. P., Ditmer, D., \& Bashaw, M. A. (2013). New graduate nurse residency: A network approach. JONA: The Journal of Nursing Administration, 43(6), 361-366.

(22) Mahmoud, A. S., \& Mohamed, H. A. (2017). Critical thinking disposition among nurses working in puplic hospitals at port-said governorate. International journal of nursing sciences, 4(2), 128-134.

(23) Mohammadi, A., Sarhanggi, F., Ebadi, A., Daneshmandi, M., Reiisifar, A., Amiri, F., \& Hajamini, Z. A. H. R. A. (2011). Relationship between psychological problems and quality of work life of Intensive Care Unit Nurses. Iranian Journal of Critical Care Nursing, 4(3), 135-140.

(24) Morsy, N. A., Shalaby, M. H., Mohamad, S., \& Elftoh, A. (2015). Educational program for Psychiatric nurses to improve their knowledge and attitude toward application of evidenced based nursing practices. Tanta Scientific Nursing Journal, 9(2), 7-28.

(25) Phillips, C., Kenny, A., Esterman, A., \& Smith, C. (2014). A secondary data analysis examining the needs of graduate 
nurses in their transition to a new role. Nurse education in practice, 14(2), 106-111.

(26) Rickbeil, P., \& Simones, J. (2012). Overcoming barriers to implementing evidence-based practice: a collaboration between academics and practice. Journal for Nurses in Professional Development, 28(2), 53-56.

(27) Sheldon, L. K., \& Hilaire, D. M. (2015). Development of communication skills in healthcare: Perspectives of new graduates of undergraduate nursing education. Journal of Nursing Education and Practice, 5(7), 30.

(28) Tastan, S., Unver, V., \& Hatipoglu, S. (2013). An analysis of the factors affecting the transition period to professional roles for newly graduated nurses in T urkey. International nursing review, 60(3), 405-412.

(29) The National Counsil of State Board of Nursing.NURSE. Com. 2013, https://www.nurse.com/blog/2013/04/22/transition-topractice-programs-may-contribute-to-new-grad-success/
(30) Tocco, N., Brunsvold, M., Kabbani, L., Lin, J., Stansfield, B., Mueller, D., \& Minter, R. M. (2013). Innovation in internship preparation: an operative anatomy course increases senior medical students' knowledge and confidence. The American Journal of Surgery, 206(2), 269279.

(31) Villanueva, D. M., Taylor, C., Dickson, C., \& Foster, J. (2015). The experiences of new graduate nurses working in a pediatric setting: a systematic review protocol of qualitative evidence. JBI Evidence Synthesis, 13(2), 49-58.

(32) Wise, T. M. (2019). Facilitating transition to practice for Millennial new graduate nurses (Doctoral dissertation, Liberty University).

(33) Zuriguel Perez, E., Lluch Canut, M. T., Falco Pegueroles, A., Puig Llobet, M., Moreno Arroyo, C., \& Roldan Merino, J. (2015). Critical thinking in nursing: Scoping review of the literature. International journal of nursing practice, 21(6), 820-830. 